\title{
EDEMA AND DECREASED RENAL BLOOD FLOW IN PATIENTS WITH CHRONIC CONGESTIVE HEART FAILURE: EVIDENCE OF "FORWARD FAILURE" AS THE PRIMARY CAUSE OF EDEMA ${ }^{1}$
}

\author{
By A. J. MERRILL \\ (From the Medical Service of Grady Hospital and the Department of Medicine, Emory \\ University School of Medicine, Atlanta)
}

(Received for publication November 14, 1945)

During the course of chronic congestive heart failure it is known that patients retain salt and water. It seems evident that this is not due to forcing of fluid into the tissues by an increased hydrostatic pressure, since such a mechanism would result in hemoconcentration, whereas chronic heart failure produces hemodilution (1, 2). Furthermore, Warren and Stead have shown that in chronic congestive failure the weight gain and blood volume increase precede the rise in venous pressure (3). This fact points to a renal factor in heart failure, and the results of an investigation of this factor by some of the newer techniques (4) is the subject of this paper.

Patients were chosen with chronic congestive failure requiring mercurial diuretics at frequent intervals to maintain compensation. This group was selected because they tended to become edematous at bed rest when diuretics were withheld and, therefore, would be expected to show at bed rest whatever abnormality was responsible for their edema. Many patients with heart disease who have become decompensated when active show no abnormality of the circulation at rest. Such patients would therefore not be expected to show any disturbance in function leading to a retention of salt and water unless observations were made during exertion.

\section{METHODS}

Patients with hypertension or obvious renal disease are excluded from the discussion in the text but a few hypertensive individuals are included in Table $I$ and Figures 1, 2 and 3 for comparison.

Because of orthopnea most patients required a 10 to 20 degree elevation at the head of the bed, and to rule out

1 The work described in this paper was done under a contract, recommended by the Committee on Medical Research, between the Office of Scientific Research and Development and the Emory University School of Medicine, Atlanta. this factor two subjects with failure were studied flat and at an elevation of 60 degrees. The renal blood flow and filtration rate, instead of falling as in a normal individual (5), remained the same.

The renal plasma flow and filtration rate were studied with sodium para-amino hippurate 2 and inulin as described by Smith et al. (4). Observations were made after a 6- to 8-hour fast. Each patient was given 2 glasses of water 30 minutes before, and phenobarbital 0.03 grams an hour before, the test. Priming doses of inulin and hippurate, calculated to give extracellular fluid and blood levels of approximately $2 \mathrm{mgm}$. per cent hippurate and $50 \mathrm{mgm}$. per cent inulin were administered. A sustaining venoclysis, which contained sufficient inulin and hippurate to maintain constant blood levels, was delivered at the rate of $4 \mathrm{ml}$. a minute. Forty minutes were allowed for equilibrium to be established between plasma and extracellular fluid. The bladder was then emptied through a catheter (4-hole when possible) by injection of $10 \mathrm{ml}$. of air and aspiration with a $50 \mathrm{ml}$. syringe. The air was reinjected, and urine and air expressed with pressure over the bladder. Then $20 \mathrm{ml}$. of distilled water followed by $30 \mathrm{ml}$. of air were introduced and aspirated. Finally, the air was reinjected and all possible residue expressed with bladder pressure alone. This entire maneuver occupied a period of one and a half minutes. Three or four 15-minute samples of urine were obtained and venous blood specimens were drawn at the mid-point. This blood was collected using metycaine as a local anesthetic since novocaine gives the same color reaction as hippurate with the coupling reagent. It was found that introducing a needle through a novocaine wheal yielded answers 4 or 5 times the true values. Patients receiving any sulfonamide preparation were excluded from the study because these drugs also contain the para-amino radical. The cells were separated from the plasma by centrifugation within an hour after collection of the blood. In man, we have not found it necessary to separate and precipitate the plasma immediately between collection periods, though Smith advises this in dogs because paraamino hippurate enters their red blood cells. Two ml. portions of plasma were precipitated by the cadmium sulfate-sodium hydroxide method and the plasma paraamino-hippuric acid level determined by a modification of the Bratton-Marshall technique for sulfonamides (6).

2 Para-amino hippurate was supplied through the courtesy of Dr. John Henderson of Sharpe and Dohme. 
One $\mathrm{ml}$. portions were precipitated with acid zinc sulfate, and inulin determinations were made by the method of Corcoran and Page (7). Urine was diluted in volumetric flasks to a urine to plasma ratio of approximately one. This was done in 2 steps, the first dilution being used for inulin determinations and the second for hippurate, starting with 5 to $10 \mathrm{ml}$. of urine measured from an accurate pipette. Standards for inulin and hippurate were made up from dilutions of the original ampules and were treated in the same manner as the unknowns. Standards were not made up from dried free acid and from dried inulin, since it is the urine to plasma ratio which determines the clearance, and exact quantitation is not necessary. All urine and blood specimens were run in duplicate and usually agreed within 2 per cent, with occasional variations of 4 per cent.

The gravimetric uranyl zinc acetate method as described by Butler and Tuthill (8) was used to determine the blood sodium. Each determination was run in duplicate and all duplicates at variance more than 2 m.eq. were discarded.

The cardiac output was determined in some of the patients usually within a few days of, and sometimes simultaneously with, the renal studies. The direct Fick principle was employed, utilizing a radiopaque ureteral catheter passed from the cubital vein to the right atrium under fluoroscopic control (9). Arterial blood was obtained from an inlying needle with a stylette in the femoral artery. The oxygen consumption was measured by the analysis of a 2-minute sample of expired air collected in a Douglas bag.

Venous pressures were estimated with a No. 19 needle connected to a glass manometer filled with normal saline, using a point $5 \mathrm{~cm}$. below the 4th right costochondral junction for a base-line, and atrial pressures were measured from the same point. Measuring from the back was not feasible on our bed (10).

\section{RESULTS}

All results were corrected to a body surface area of $1.73^{\circ}$ square meters to make them comparable. Thirty-nine studies on thirty-five normal individuals without evidence of renal dişease or hypertension gave average figures of $626 \mathrm{ml}$. per minute per 1.73 square meters for the renal plasma flow, $123 \mathrm{ml}$. per minute for filtration rate, and 20.6 per cent for the filtration fraction. The mean value for renal plasma flow was $626 \pm 165 \mathrm{ml}$. per minute per 1.73 square meters; for filtration rate, $129 \pm 40 \mathrm{ml}$. per minute per 1.73 square meters excluding three patients who were far out of line. We did not find the filtration fraction (RPF/FR) so constant as did Goldring and Chassis (11), the mean being $20.6 \pm 5.6$ per cent. Eight patients had filtration fractions outside of 20 per cent \pm 5 . Two of the latter were studied a second time with essentially the same results. It is possible that some of our patients were abnormal as many came from the older age groups. The wide variation of the renal plasma flow and filtration rate is partially accounted for by the fact that both males and females are included. The means of Goldring and Chassis were $697 \pm$ $135.9 \mathrm{ml}$. per minute per 1.73 square meters renal plasma flow for males, and $594 \pm 102.4 \mathrm{ml}$. per minute for females; $131 \pm 21.5 \mathrm{ml}$. per minute per 1.73 square meters filtration rate for males, and $117 \pm 15.6 \mathrm{ml}$. per minute per 1.73 square meters for females. The mean filtration fraction was 20 \pm 0.03 per cent (11).

In the patients with chronic failure the renal plasma flow was reduced to one-third to one-fifth normal. The filtration rate was one-half to onethird normal, giving filtration fractions ranging from 30 to 50 per cent (Table I). The filtration fraction is obtained by dividing the filtration rate by the renal plasma flow. It represents the percentage of the renal plasma flow which is filtered. High values indicate a high filtration pressure, probably most frequently due to efferent arteriolar constriction (12).

Figure 1 shows the results of renal studies in cardiac failure on the same and different subjects at various venous pressures. There is no significant correlation between venous pressure levels and inulin and hippurate clearances. In many patients these studies were repeated after the venous pressure was lowered by mercurial diuretics. The renal blood flow remained low despite the change in venous pressure. An increase in renal blood flow in some patients was observed when digitalis was given, or. when the cardiac output increased during the period of observation. For this reason a decrease in venous pressure was at times associated with a rise in renal plasma flow. Two patients with acute failure had a normal cardiac output at rest and a normal renal plasma flow despite a high venous pressure. These patients made a rapid recovery. The lack of correlation between the venous pressure and the renal blood flow is even more evident in these patients with acute failure.

Figure 2 shows the correlation between the renal plasma flow and the cardiac index. The cardiac index is the cardiac output per square meter of body surface area, and the normal range in our 


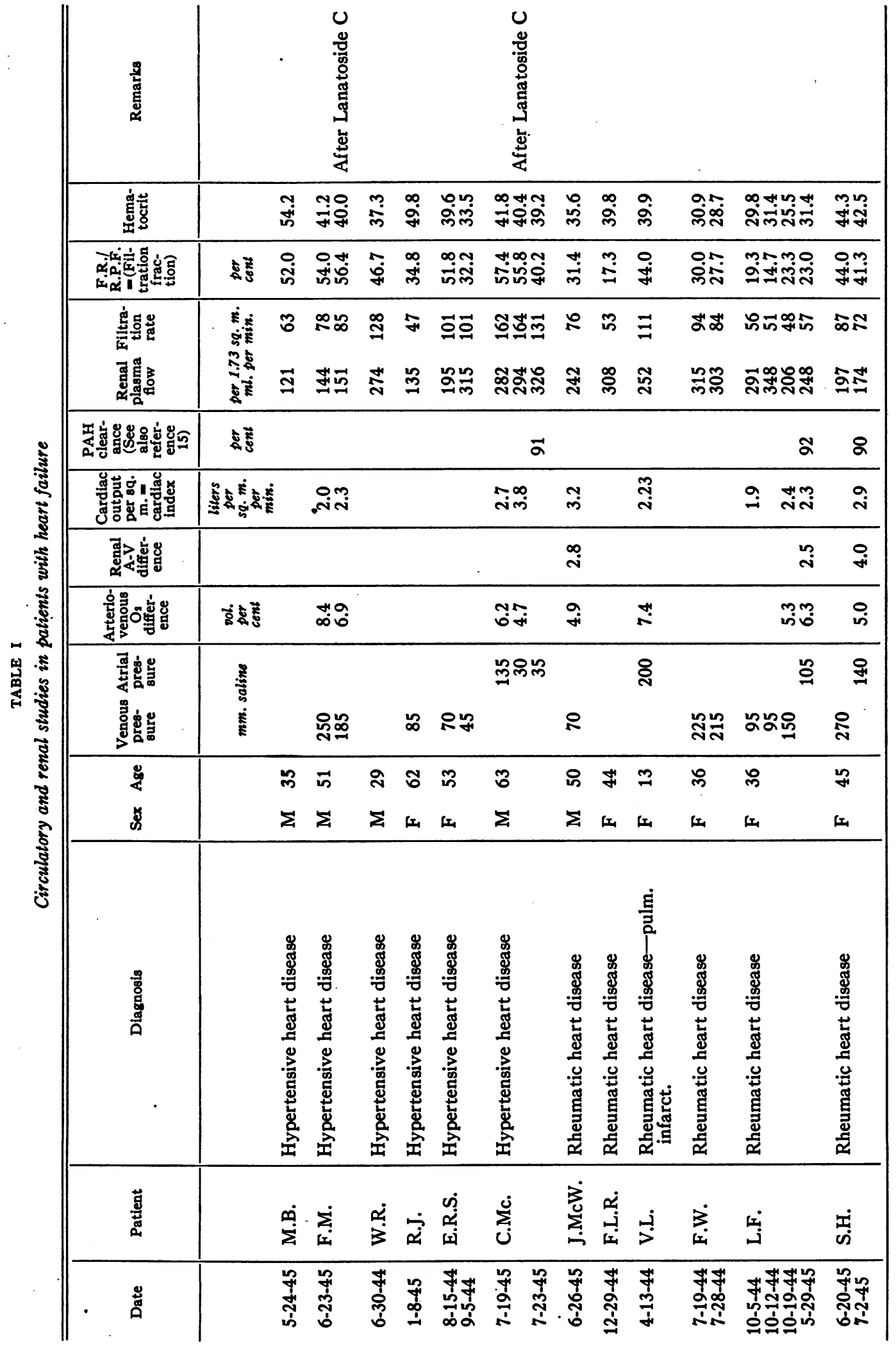


A. J. MERRILL

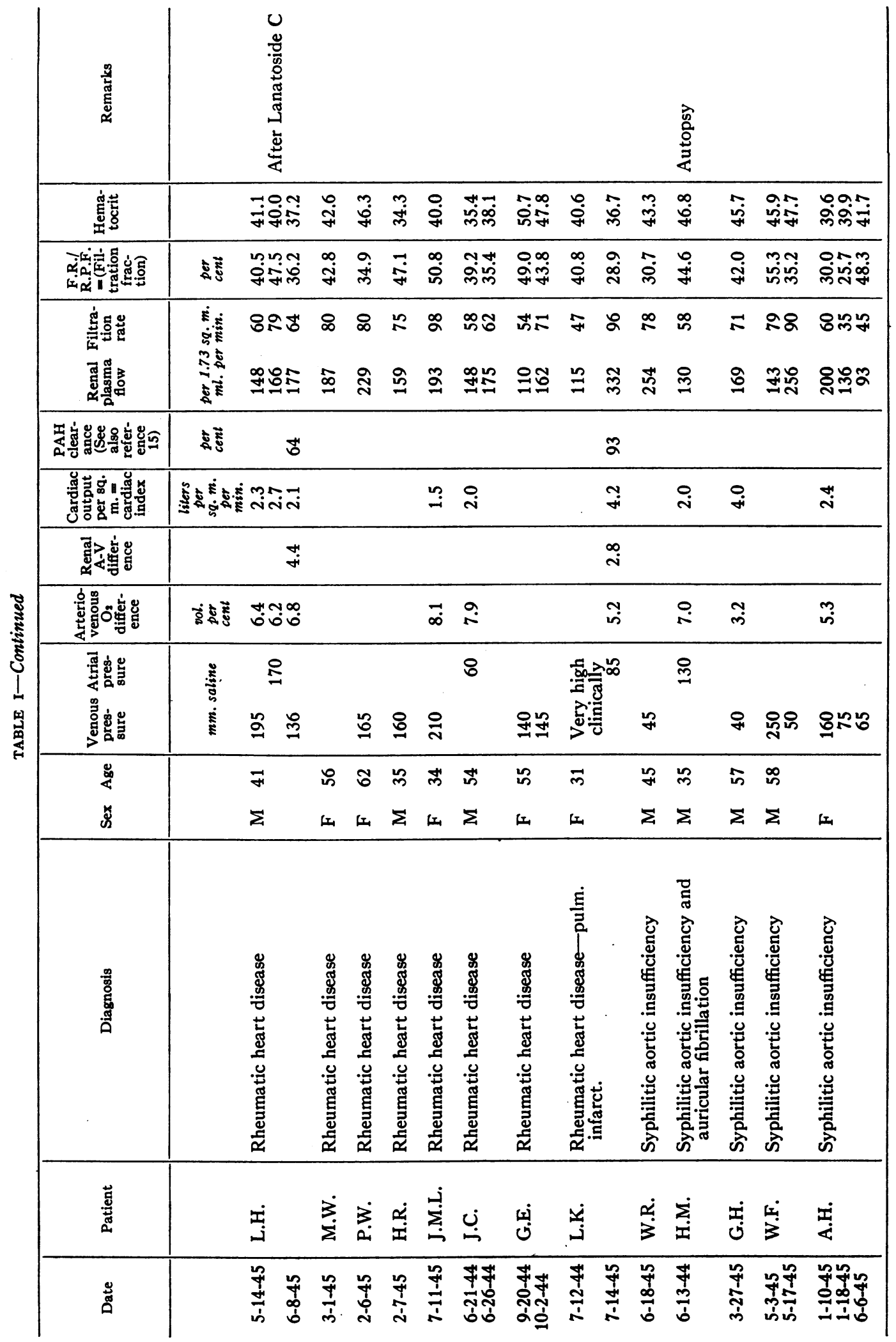


EDEMA IN CHRONIC CONGESTIVE HEART FAILURE

\begin{tabular}{|c|c|c|c|c|c|c|c|c|c|c|c|c|c|c|}
\hline 题 & & & 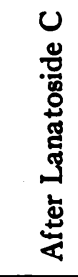 & & 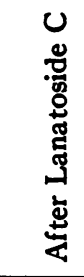 & 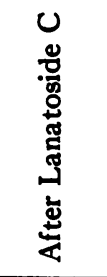 & 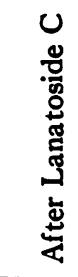 & & & 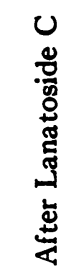 & & & & 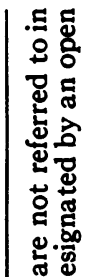 \\
\hline 葛 & & & 品 & $\hat{\bar{p}}$ & กั & å̀ & $\begin{array}{l}\text { 울 } \\
\text { inj }\end{array}$ & $\stackrel{\circ}{\infty}$ & $\begin{array}{c}\infty \\
\stackrel{0}{0} \\
\dot{N}\end{array}$ & 움여 & $\stackrel{\infty}{\text { लें }}$ & 芦 & : & 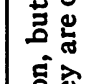 \\
\hline 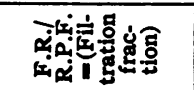 & $\$$ & 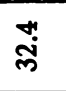 & 象 & 苟 & జָׁ & 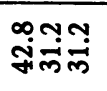 & 薃吕 & 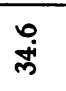 & 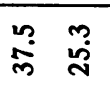 & n̊ㅇํ & ஜ் & @i & 迥 & . \\
\hline 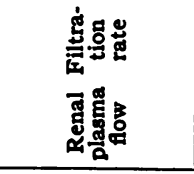 & 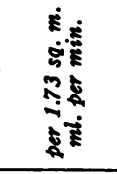 & $\begin{array}{c}\text { ส } \\
\text { ลี }\end{array}$ & 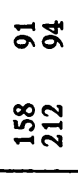 & 욤 & 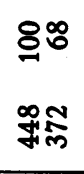 & 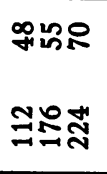 & $\begin{array}{l}80 \\
\text { ?뮤 }\end{array}$ & $\begin{array}{l}a \\
\stackrel{N}{N}\end{array}$ & 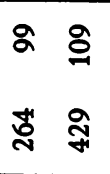 & $\begin{array}{l}\text { aేळ } \\
\text { 듬요 }\end{array}$ & $\begin{array}{l}\ddot{n} \\
\Xi\end{array}$ & $\begin{array}{l}\text { ๓ } \\
\infty\end{array}$ & $\begin{array}{l}? \\
\stackrel{2}{1}\end{array}$ & 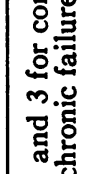 \\
\hline 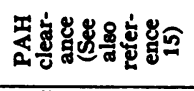 & \& & & & & & & & $\infty$ & ๓å & & & & $\ddot{\infty}$ & 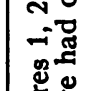 \\
\hline 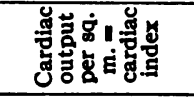 & 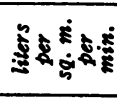 & & ஸై & $\stackrel{\pi}{i}$ & & ด्रing & $\stackrel{a}{i}$ & $\stackrel{0}{i}$ & $\stackrel{m}{m}$ & $\stackrel{m}{i}$ & 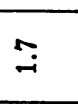 & 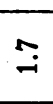 & $\stackrel{0}{-}$ & 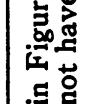 \\
\hline 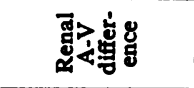 & & & & & & & & & $\stackrel{\infty}{\sim}$ & & & & in & \\
\hline 宓 & वेईदे & & ang & $\stackrel{0}{\circ}$ & & $\stackrel{a}{a} \underset{+}{a}+\dot{+}$ & $\stackrel{\oplus}{m}$ & กั & in & $\stackrel{0}{\circ \infty}$ & 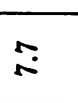 & $\stackrel{9}{\circ}$ & 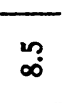 & 要 \\
\hline 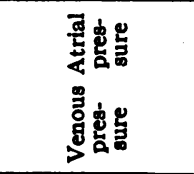 & 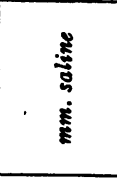 & & 조뉴 & 8 & & ลีก & $\mathfrak{⿰}$ & ఋ & น & $\stackrel{2}{2}$ & 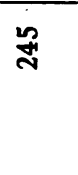 & $\stackrel{n}{\sim}$ & & 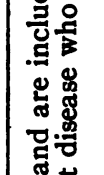 \\
\hline 过 & & 욱 & $\infty$ & $\ddot{m}$ & हే & $\ddot{m}$ & & $f$ & $F$ & ి్లి & $\approx$ & ల్లు & 2 & 串 \\
\hline ช̆ & & $\Sigma$ & $\Sigma$ & $\Sigma$ & 14 & $\Sigma$ & L & $\Sigma$ & $\Sigma$ & $\Sigma$ & $\Sigma$ & $\Sigma$ & $\Sigma$ & 呇. \\
\hline 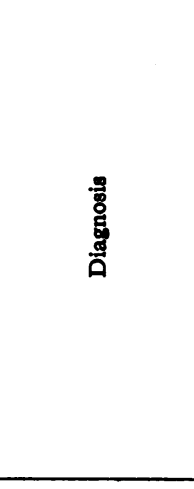 & & 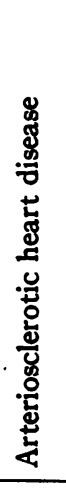 & 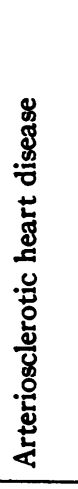 & 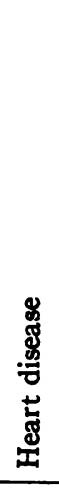 & 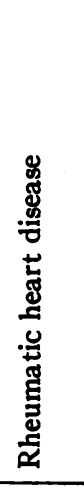 & 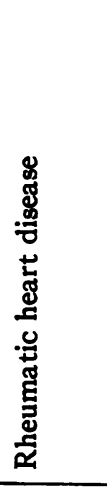 & 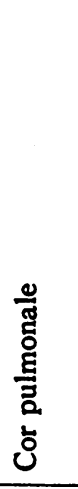 & 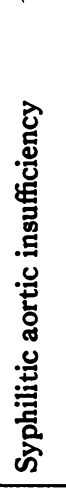 & 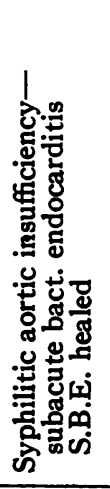 & 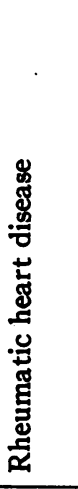 & 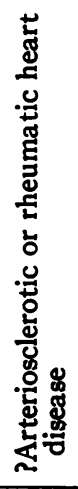 & 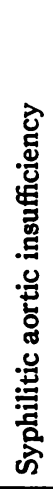 & 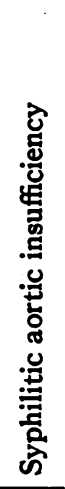 & 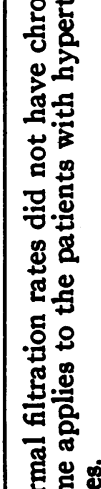 \\
\hline 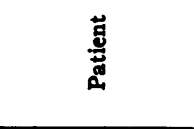 & & $\ddot{\varphi}$ & 安 & $\dot{v}$ & $\dot{\mathscr{\alpha}}$ & $\stackrel{\text { ஸे }}{H}$ & $\begin{array}{l}\dot{0} \\
z\end{array}$ & بُ & 迎 & $\stackrel{ن}{\dot{m}}$ & نे & ن & $\underset{\dot{z}}{\dot{\Sigma}}$ & 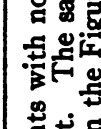 \\
\hline ڤั & & $\underset{7}{\sharp}$ & 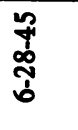 & 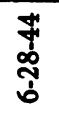 & $\begin{array}{l}\frac{7}{7} \\
\stackrel{0}{0}\end{array}$ & 尔 & 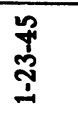 & 年 & 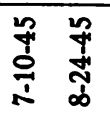 & 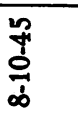 & ‡̊ & 尔 & 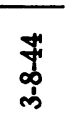 & 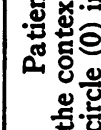 \\
\hline
\end{tabular}




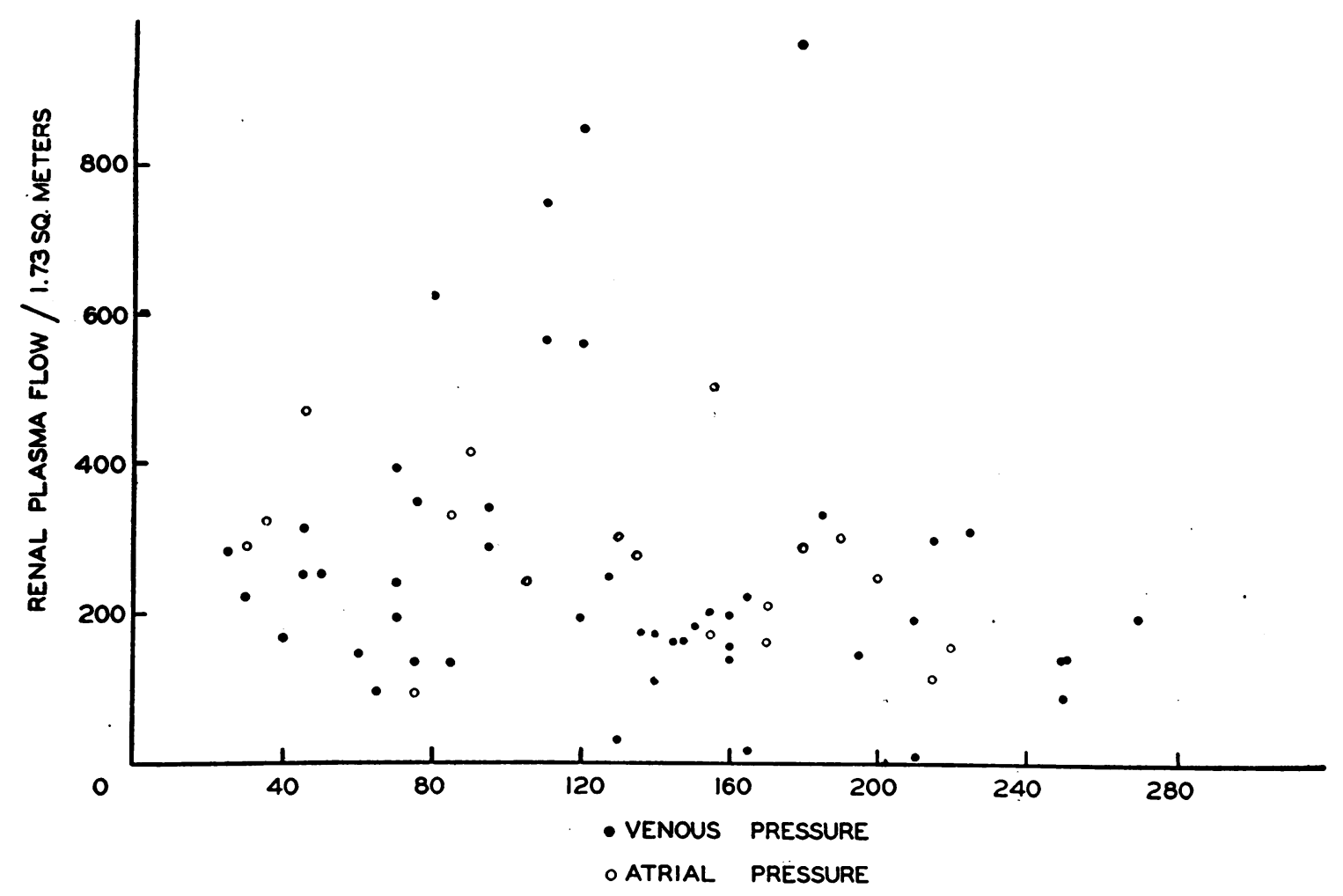

Fig. 1. Renal Plasma flow at Various Venous Pressure Levels in Patients with Congestive Heart Failure

Correlation coefficient $r=-0.1750$. Pr is greater than 0.10 , indicating no significant correlation.

laboratory is 2.3 to 4.1 , with an average of 3.3 liters per square meter per minute (13). In general the renal plasma flow tended to fall as the cardiac index decreased. Two patients, G. H. and N. G., had a normal cardiac index with a low renal blood flow. It is possible that they had renal disease although this was not investigated.

From Figure 2 it is obvious that in many of the patients the absolute figure for the cardiac index is within the normal range. As pointed out previously there is no absolute level of the cardiac index below which patients develop cardiac failure (14). The cardiac index must be considered in relation to the metabolic needs of the subject. Thus patients with thyrotoxicosis may have cardiac failure with an output that is far above the normal resting level, but one which is inadequate for the increased metabolism. In many patients with cardiac failure and dyspnea the metabolic rate is increased. In these subjects the cardiac index may be in or above the normal range for resting subjects and heart failure still be present.
That the circulation was not optimum for the needs of our patients is shown by the increased arteriovenous oxygen differences. Figure 3 shows the renal blood flow plotted against the arteriovenous oxygen difference. In the great majority of the patients studied the arteriovenous difference was increased beyond the average normal value of 4 volumes per cent found in this laboratory (13), and that of 4.5 volumes per cent found in another laboratory (15).

The amount of sodium filtered was calculated from the product of the filtration rate times the blood sodium level. The amount of sodium excreted was calculated directly from the urine sodium, and the difference represents the amount resorbed. Twelve normals were studied and they showed an average value of $18.09 \mathrm{~m}$. eq. sodium filtered per minute, $0.22 \mathrm{~m}$. eq. excreted, and 1.23 per cent of filtered sodium excreted. In the patients with heart failure, one may see there was a definite decrease in the amount of sodium filtered, due to the low filtration rate (Table II). The 


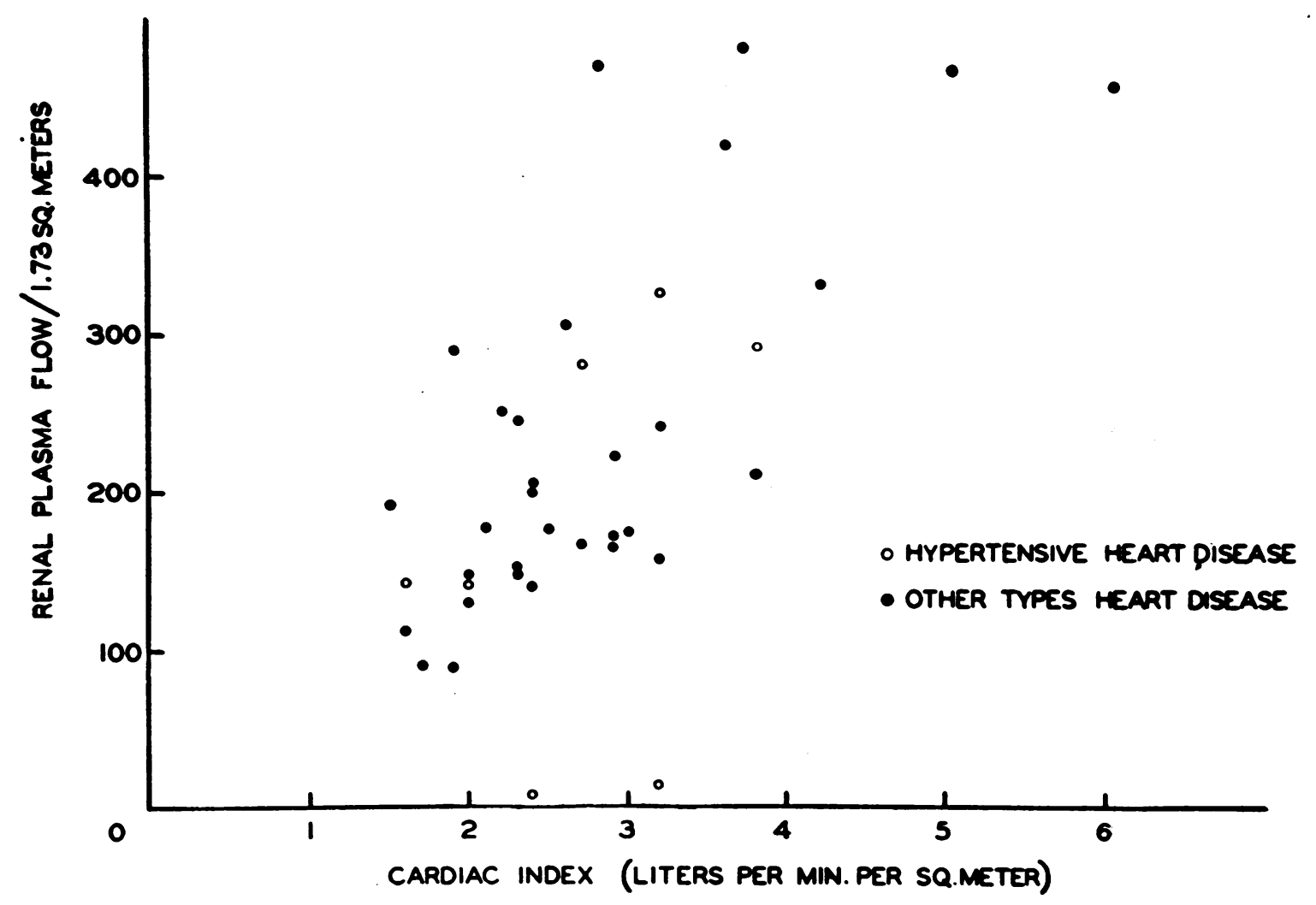

Fig. 2. Renal Plasma Flow Correlated with Cardiac Index in Patients with Congestive Failure Correlation coefficient $r=0.6393$. $\mathrm{Pr}$ is less than 0.10 , indicating a high degree of correlation.

amount of sodium excreted per minute is also diminished. The percentage of the filtered sodium excreted is related to some interesting factors which bear upon the control of sodium excretion in normal individuals. Experiments clarifying these relationships have been done and will be reported in a separate communication.

\section{DISCUSSION}

The reduction in renal blood flow in patients with chronic heart failure is so marked that the question immediately arises as to whether or not the method is valid in heart failure. The method is dependent upon the almost complete removal of hippurate in a single passage through the kidney. To see if this occurred in heart failure, blood was obtained by passing a catheter into the renal vein of cardiac patients in whom the renal blood flow was being measured by the hippurate technique (16). The hippurate concentration in this blood was compared with that of the arterial blood collected simultaneously. The results in Table I in- dicate a normal clearance even in patients with severe heart failure. The calculations for the renal plasma flow were corrected to the average clearance figure of 88 per cent in the two cases in which the clearance was distinctly below normal. One of these, L. H., had severe pyelonephritis in addition to his heart failure. The other, J. C., died of multiple pulmonary infarctions. Autopsy showed only severe renal congestion and edema. As may be seen, two of the most severe cases of failure, M. R. and S. H., cleared normally. Seymour et al. (2) found normal renal tubular concentrating ability in patients with failure. Van Slyke et al. (17) showed that in shock the renal blood flow could be reduced to as low as 3 per cent without decreasing the percentage extraction of hippurate by the kidneys. They also demonstrated (17) that the kidney differs from muscles, brain and other tissues in that the arteriovenous oxygen difference does not rise proportionately as the renal blood flow falls. A reduction to 20 per cent of normal in the renal blood flow produces no 


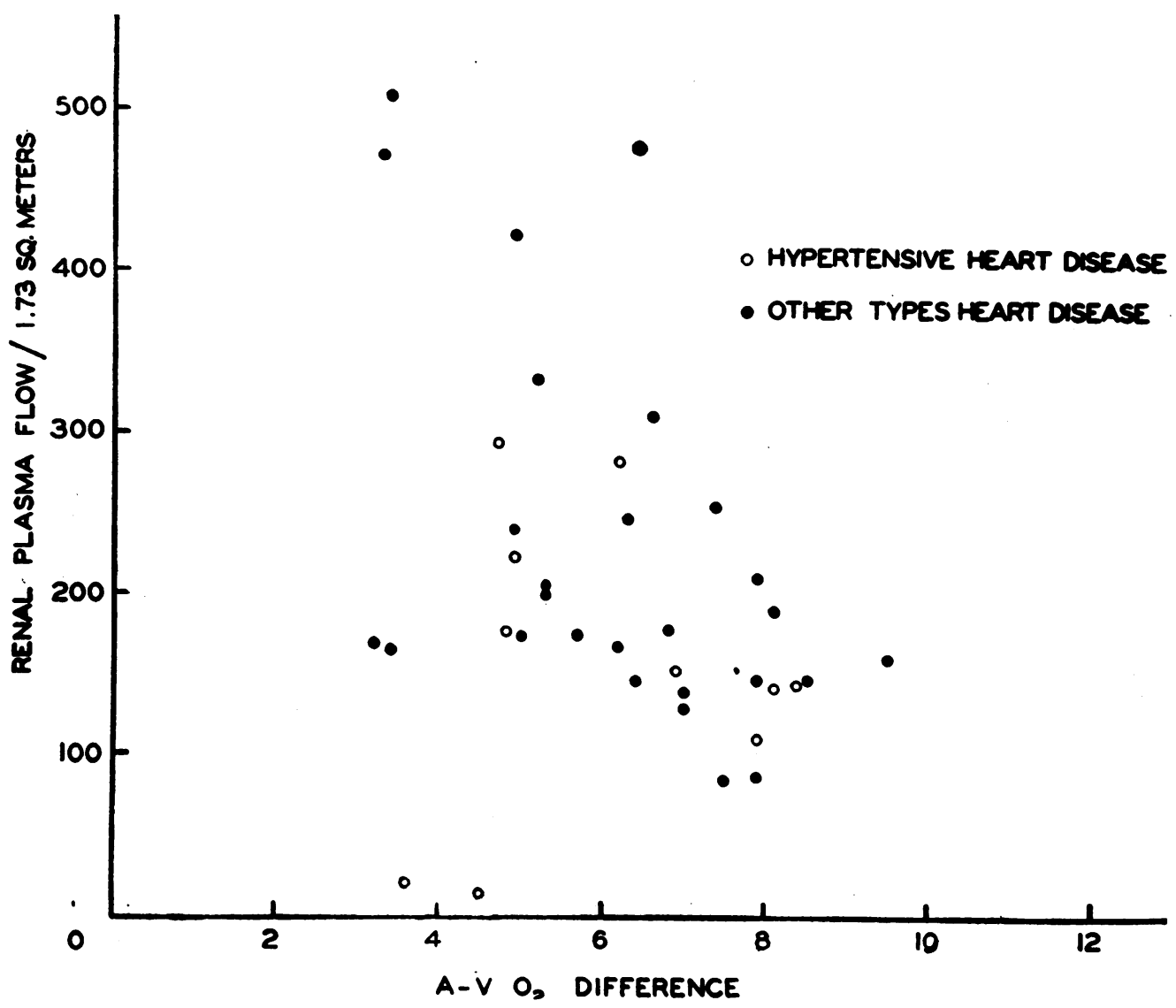

Fig. 3. Renal Plasma flow Plotted against the Arteriovenous Oxygen Difference Correlation coefficient $r=-0.4078$. $P r$ is less than 0.05 and greater than 0.02 , indicating a significant correlation.

change in the amount of oxygen removed by the kidney. The renal blood flow of dogs in shock was reduced far out of proportion to the reduction in cardiac output, and they interpreted this as a saving mechanism to tissues more susceptible to anoxemia, such as the brain. The same mechanism seems to operate in patients with chronic congestive heart failure with a low cardiac output. In many of our patients the renal arteriovenous oxygen difference was increased. This is further evidence that the renal blood flow is actually markedly decreased, and that the low values are not the result of experimental error.

Our results are incompatible with the "backward failure" concept of edema formation in chronic heart failure, and point instead to a "forward failure" pathogenesis. In chronic congestive heart failure the low renal blood flow has no relationship to the height of the venous pressure either in the same or different individuals. It can be correlated with an inadequate cardiac output. The cardiac output is rarely reduced below one-half the normal resting value, while the renal blood flow is frequently reduced to approximately one-fifth normal. This indicates a specific diversion of blood away from the kidneys, organs which with the subject at rest normally receive about 20 per cent of the cardiac output. The fact that the filtration rate remains relatively normal until the renal blood flow is markedly reduced suggests a high intraglomerular pressure from efferent arteriolar constriction (12). It is well known that renin, the renal pressor substance, causes efferent arteriolar constriction (18). By a technique previously described we have obtained blood directly from the renal vein in unanesthetized patients with chronic congestive failure (17). Preliminary bioassays (19) of this blood show a considerable 
TABLE II

Excretion of sodium in patients with chronic heart disease

\begin{tabular}{|c|c|c|c|c|c|c|c|c|c|}
\hline \multirow[b]{2}{*}{ Date } & \multirow[b]{2}{*}{ Patient } & \multirow[b]{2}{*}{ Diagnosis } & \multirow{2}{*}{$\begin{array}{c}\text { Renal } \\
\text { plasma } \\
\text { flow }\end{array}$} & \multirow{2}{*}{$\begin{array}{c}\text { Filtra- } \\
\text { tion } \\
\text { rate }\end{array}$} & \multirow{2}{*}{$\begin{array}{l}\text { F.R.l } \\
\text { R.P.F. } \\
\text { (Fil- } \\
\text { tration } \\
\text { frac- } \\
\text { tion) }\end{array}$} & \multicolumn{2}{|c|}{ Sodium } & \multirow{2}{*}{$\underset{\text { cretion }}{\text { Ex- }}$} & \multirow[b]{2}{*}{ Diuretics } \\
\hline & & & & & & $\begin{array}{c}\text { Amount } \\
\text { fil- } \\
\text { tered }\end{array}$ & $\begin{array}{c}\text { Amount } \\
\text { ex- } \\
\text { creted }\end{array}$ & & \\
\hline & & & \multicolumn{2}{|c|}{$\begin{array}{l}\text { per } 1.73 \text { sq. m. } \\
\text { ml. per mix. }\end{array}$} & $\begin{array}{l}\text { per } \\
\text { cent }\end{array}$ & \multicolumn{2}{|c|}{ m. eq. per min. } & $\begin{array}{l}\text { per } \\
\text { cent }\end{array}$ & \\
\hline $3-1-45$ & M.W. & Rheumatic heart disease & 187 & 80 & 43.0 & 10.7 & .153 & 1.4 & Salyrgan 48 hrs. before \\
\hline $1-10-45$ & A.H. & Syphilitic aortic insufficiency & 200 & 60 & 30.0 & 8.22 & .08 & .975 & Salyrgan 1 week before \\
\hline $\begin{array}{l}10-5-44 \\
10-12-44 \\
10-19-44 \\
5-29-45\end{array}$ & L.F. & Syphilitic aortic insufficiency & $\begin{array}{l}291 \\
348 \\
206 \\
248\end{array}$ & $\begin{array}{l}56 \\
51 \\
48 \\
57\end{array}$ & $\begin{array}{l}19.1 \\
14.7 \\
23.1 \\
23.0\end{array}$ & $\begin{array}{l}6.93 \\
6.24 \\
7.46\end{array}$ & $\begin{array}{l}.05 \\
.02 \\
.10\end{array}$ & $\begin{array}{c}.72 \\
.317 \\
1.34\end{array}$ & $\begin{array}{l}\text { Salyrgan } 1 \text { week before } \\
\text { Salyrgan } 4 \text { days before } \\
\text { Salyrgan } 11 \text { days before } \\
\text { Salyrgan } 24 \text { hrs. before }\end{array}$ \\
\hline $5-14-45$ & L.H. & Rheumatic heart disease & 148 & 60 & 40.5 & 8.3 & .0033 & .039 & \\
\hline $8-10-45$ & J.G. & Rheumatic heart disease & 151 & 91 & 60.5 & 11.9 & .0013 & .011 & \\
\hline
\end{tabular}

amount of renin (20). Increase in renin associated with a low cardiac output has been described in shock (21). A decrease in the amount of blood available to the kidney is supposed to be the fundamental cause of the increase in renin (22).

We attribute the salt retention, which in chronic congestive heart failure results in edema, to a low filtration rate which is caused by a marked reduction in renal blood flow. The data reported here demonstrate that the tubules continue to reabsorb salt at a fairly normal rate. The reason for this is not known, but it is probably related to their fundamental sodium-conserving mechanism. The decreased amount of sodium filtered in the presence of normal or slightly decreased reabsorption accounts for the fact that edema in cardiac failure develops with the quantity of sodium present in the average diet. Sodium retention will occur in normal subjects if the intake of sodium is greatly increased. Lyons showed that salt and water retention can produce a rise in venous pressure by adminstering large quantities of salt solution to normal people (23). Venous pressures as high as $170 \mathrm{~mm}$. were observed. La Due found elevated venous pressures in some patients with acute glomerulonephritis without other evidence of heart failure (24). This was probably due to the low filtration rate produced by disease of Bowman's capsule (25).

Seymour et al. (2) found that the renal blood flow and filtration rate were decreased in patients with failure from hypertensive heart disease.
After digitalization and compensation of the patient; the renal blood flow rose while the filtration rate was relatively unchanged. They believed that the low renal blood flow and relatively high filtration rate during failure were due to the high venous pressure, because as compensation was restored the venous pressure fell and the renal blood flow increased out of proportion to the change in filtration rate. However, in each case which they report, a rise in cardiac output was present after compensation was restored by the use of digitalis, and it is to this that we attribute the rise in renal blood flow. The relatively high filtration rates were probably caused by efferent arteriolar constriction.

The evidence against "backward failure" or increased venous hydrostatic pressure as the cause of chronic cardiac edema is strong. It has been suggested that a slight rise of venous pressure which does not at first exceed the limits of normal produces the early edema in chronic heart failure. The fact that the gain in weight and the increase in blood volume precede a measurable rise in venous pressure indicates that a rise in capillary and venous pressures does not occur initially. A primary increase in venous and capillary pressures would cause hemoconcentration rather than hemodilution such as is found in chronic congestive failure.

Patients with acute heart failure associated with a sudden decrease in cardiac output may have a rise in venous pressure due to redistribution of 
blood in the venous system produced by venoconstriction (26). The patients of Reichsman and Grant who had auricular fibrillation and were permitted to go into failure by omitting digitalis showed an initial rise in venous pressure followed by a gain in weight (27). They probably have a similar mechanism for their rise in venous pressure. Such subjects are not suitable for determination of the mechanism of sodium retention in heart failure, because a decrease in cardiac output and a rise in venous pressure occur simultaneously, and there is no means of telling which factor is responsible.

The low renal blood flow of patients with chronic heart failure might have resulted from pressure on the arterioles and veins from greatly swollen kidneys constricted by a tight capsule. In several patients with failure the venous pressure was reduced to normal with mercurial diuretics and kept at a normal value for several days. The renal blood flow remained essentially the same, demonstrating that a swollen kidney did not cause a reduction in renal blood flow.

Futcher and Schroeder (28) demonstrated the inability of the kidney to excrete salt properly in congestive failure by measuring the rate of excretion of salt in the urine after a venoclysis of concentrated salt solution. They found that cardiac subjects eliminated this salt much more slowly than normal controls. They attributed this to increased reabsorption of salt by the tubules. Our data on sodium excretion and reabsorption indicate that tubular reabsorption is not increased, and that the decreased output of sodium results from a decrease in the amount of sodium filtered, rather than an increase in the amount reabsorbed. These studies will be reported in detail elsewhere.

Several objections to the thesis that cardiac edema is caused by a reduction in renal blood flow arise. Many patients who are compensatable by bed rest alone, and who fail only with exertion, have a normal cardiac output and renal blood flow at rest (29). It is believed that these patients will . be found to have an inadequate cardiac output and a low renal blood flow if they are studied under the conditions during which they developed the signs of heart failure; namely, during exertion or in the presence of infection. Studies on this problem are under way. A somewhat similar situation is found in patients with thyrotoxicosis, anemia and beri-beri, who at rest may have failure with supernormal cardiac outputs. When the requirements for blood rise, as in anemia and thyrotoxicosis, the cardiac output may become inadequate for the increased demand for blood, even though the resting cardiac output still exceeds the value found in normal subjects. When the cardiac output is inadequate for the body needs, the kidneys, through a humoral or reflex mechanism, direct part of their blood supply elsewhere. Practically every patient with severe anemia has a decrease in renal blood flow, despite a marked rise in cardiac output $(30,31)$. In three patients - with heart failure, two with anemia and one with thyrotoxicosis, a marked reduction in renal blood flow was found (28). In the thyrotoxic patient the renal blood flow rose to a supernormal value as the venous pressure fell and the edema disappeared. One of the anemia patients had a normal renal blood flow after recovery. The other did not, and was found to have renal disease.

Hypertensive patients who may have low filtration rates without edema are able to respond to exercise with an increase in cardiac output, and the shunting mechanism suggested above is not brought into play.

Patients with renal disease which has progressed to the point of uremia all have low filtration rates, many lower than any of our cardiac patients. Most of these individuals seen in this hospital during the past two years have had edema and/or an elevated venous pressure. Those without edema or elevated venous pressure have had nausea and vomiting and were unable to take salt and water. $\mathrm{Hy}$ dration with salt and water intravenously promptly brought edema and elevated venous pressure.

Individual $\vec{s}$ with shock have very low filtration rates and yet rarely develop edema. The duration of shock is usually too short for the accumulation of salt and water. However, in prolonged shock edema may develop without other evidence of congestive heart failure (32).

The demonstration that salt and water are retained in patients with chronic cardiac decompensation on the basis of "forward failure" in no way invalidates the "backward failure" theory of pulmonary congestion. All of the phenomena observed on the ward are in accord with the concept that the left ventricle usually fails before the right. The assumption that this causes a rise in venous 
pressure in the lungs seems acceptable. This rise in venous pressure may be responsible for the fact that fluid not excreted by the kidneys because of "forward failure" is deposited so early and extensively in the lungs. During the day the high capillary and venous pressures produced in parts of the body lying below the heart cause fluid to be forced into the tissues in the dependent portions of the body. It is believed that, when the patients lie down, this fluid is mobilized and is redeposited in the lungs because of the abnormally high capillary pressure from failure of the left ventricle. A reduction in renal blood flow is the primary cause of the retention of salt and water, but local changes in venous and capillary pressures produced by gravity and left ventricular failure determine where the retained fluid is deposited.

\section{SUMMARY AND CONCLUSIONS}

1. Patients with chronic congestive heart failure without evidence of hypertension or renal disease were studied to determine the rôle of the kidney in the formation of cardiac edema. These patients tended to have an inadequate cardiac output by the catheter method utilizing the direct Fick principle, and a low renal blood flow by the para-amino hippurate method.

2. The filtration rate by the inulin technique was reduced only about half as much as the renal plasma flow, frequently giving filtration fractions higher than those reported in any other condition. This indicates a high intraglomerular pressure, which was probably caused by efferent arteriolar constriction.

3. Studies of sodium filtration, excretion and reabsorption show that the retention of salt resulting in edema is caused by the low filtration rate, and is not due to increased reabsorption of salt.

4. The renal blood flow was reduced to about one-fifth normal, when the cardiac output was approximately half normal, indicating a specific diversion of blood away from the kidney.

5. It is suggested that a similar shunting of blood from the kidneys may be important in those patients who have a normal renal blood flow and normal cardiac output at rest, but who develop evidence of heart failure and edema on exertion. When the cardiac output becomes inadequate to meet the demands of exercise, blood may be diverted from the kidneys to other parts of the body whose metabolic needs are greater.

6 . The reduction in renal blood flow had no relation to the venous pressure, but was correlated with the reduction in cardiac output, indicating that it is a "forward failure" phenomenon and not due to "backward failure" or increased hydrostatic pressure in the veins.

This work was done with the technical assistance of Miss Georgia Coleman, Miss Marguerite Acuff, Miss Eloise Cavin, Miss Lois Jackson and Mrs. Dorothy Hall Graham. Statistical analyses were by Mrs. Charles Stone, Jr.

\section{BIBLIOGRAPHY}

1. Gibson, J. G., and Evans, W. A., Jr., Clinical studies of the blood volume. Changes in blood volume, venous pressure and blood velocity rate in chronic congestive heart failure. J. Clin. Invest., 1937, 16, 851.

2. Seymour, W. B., Pritchard, W. H., Longley, L. P., and Hayman, J. M., Jr., Cardiac output, blood and interstitial fluid volumes, total circulating serum protein and kidney function during cardiac failure and after improvement. J. Clin. Invest., 1942, 21, 229.

3. Warren, J. V., and Stead, E. A., Jr., Fluid dynamics in chronic congestive heart failure. Arch. Int. Med., 1944, 73, 138.

4. Smith, H. W., Goldring, W., and Chasis, H., Measurement of the tubular excretory mass, effective blood flow and filtration rate in the normal human kidney. J. Clin. Invest., 1938, 17, 263.

5. Smith, H. W., Lectures on the Kidney. University Extension Division, University of Kansas, Lawrence, Kansas, 1943, p. 57.

6. Smith, H. W., Personal communication.

7. Corcoran, A. C., and Page, I. H., Applications of diphenylamine in determination of levulose in biological media; determination of inulin; determination of levulose in small amounts of blood. J. Biol. Chem., 1939, 127, 601.

8. Butler, A. M., and Tuthill, E., An application of the uranyl zinc acetate method for the determination of sodium in biological material. J. Biol. Chem., 1931, 93, 171.

9. Cournand, A., and Ranges, H. A., Catheterization of the right auricle in man. Proc. Soc. Exper. Biol. and Med., 1941, 46, 462.

10. Lyons, R. H., Kennedy, J. A., and Burwell, C. S., Measurement of venous pressure by a direct method. Am. Heart J., 1938, 16, 675.

11. Goldring, W., and Chasis, H., Hypertension and Hypertensive Disease. Commonwealth Fund, New York, 1944, p. 56. 
12. Smith, H. W., Lectures on the Kidney. University Extension Division, University of Kansas, Lawrence, Kansas, 1943, p. 51.

13. Stead, E. A., Jr., Warren, J. V., Merrill, A. J., and Brannon, E. S., The cardiac output in male subjects as measured by the technique of right atrial catheterization. Normal values with observations on the effect of anxiety and tilting. J. Clin. Invest., 1945, 24, 326.

14. Brannon, E. S., Merrill, A. J., Warren, J. V., and Stead, E. A., Jr., The cardiac output in patients with chronic anemia as measured by the technique of right atrial catheterization. J. Clin. Invest., 1945, 24, 332.

15. Cournand, A., Riley, R. L., Breed, E. S., Baldwin, E. DeF., and Richards, D. W., Measurement of cardiac output in man using the technique of catheterization of the right auricle or ventricle. J. Clin. Invest., 1945, 24, 106.

16. Brannon, E. S., Merrill, A. J., and Warren, J. V., Studies of the renal extraction of oxygen and paraamino hipppurate in normal subjects and in patients with anemia and chronic congestive failure. To be published.

17a. Van Slyke, D. D., Personal communication.

b. Dole, V. P., Emerson, K., Jr., Phillips, R. A., Hamilton, P. B., and Van Slyke, D. D., The renal extraction of oxygen in experimental shock. Am. J. Physiol., 1946, 145, 3.

18. Merrill, A. J., Williams, J. R., Jr., and Harrison, T. $R$., The site of action of the renal pressor substance. Am. J. M. Sc., 1938, 196, 18.

19. Dexter, L., Personal communication.

20. Merrill, A. J., Morrison, J., and Brannon, E. S., Unpublished data.
21. Dexter, L., Frank, H. A., Haynes, F. W., and Altschule, M. D., Traumatic shock. The effect of hemorrhagic shock on the concentration of renin and hypertensinogen in the plasma of unanesthetized dogs. J. Clin. Invest., 1943, 22, 847.

22. Goldblatt, H., Studies on experimental hypertension. The pathogenesis of experimental hypertension due to renal ischemia. Ann. Int. Med., 1937, 11, 69.

23. Lyons, R. H., Jacobson, S. D., and Avery, N. L., Increases in the plasma volume following the administration of sodium salts. Am. J. M. Sc., 1944, 208, 148.

24. La Due, J. S., The role of congestive heart failure in the production of the edema of acute glomerulonephritis. Ann. Int. Med., 1944, 20, 405.

25. Earle, D. P., Jr., Taggart, J. V., and Shannon, J. A., Glomerulonephritis. A survey of the functional organization of the kidney in various stages of diffuse glomerulonephritis. J. Clin. Invest., 1944, 23, 119.

26. Cooper, F. W., Stead, E. A., Jr., and Warren, J. V., The beneficial effects of intravenous infusions in acute pericardial tamponade. Ann. Surg., 1944, 120, 822.

27. Reichsman, F., and Grant, H., Personal communication.

28. Futcher, P. H., and Schroeder, H. A., Studies on congestive heart failure. Impaired renal excretion of sodium chloride. Am. J. M. Sc., 1942, 204, 52.

29. Merrill, A. J., and Brannon, E. S., Unpublished data.

30. Merrill, A. J., Unpublished data.

31. Bradley, S. E., Medical progress. Modern concepts of renal structure and function in chronic Bright's disease. New England J. Med., 1944, 231, 452.

32. Stead, E. A., Jr., Unpublished data. 